\title{
Impact of wind energy development on birds and bats: the case of Adama wind farm, Central Ethiopia
}

\author{
Weldemariam Tesfahunegny ${ }^{1 *}$, Demeke Datiko², Mengistu Wale², Gebre Egziabeher Hailay ${ }^{2}$ and \\ Tadesse Hunduma²
}

\begin{abstract}
Background: In contrast to wind farm collision, birds and bats were understudied and their occurrence and function were poorly understood. Here, study on mortality of iconic bird and bat species were conducted on Adama I and II wind farms during wet (August 2018) and dry (March 2019) seasons.

Materials and methods: The methodology employed carcass searches using direct physical inspections, semi-structured interviews $(n=50)$, and focus group discussions of wind farm officials and farmers around Adama I and II wind farms. Descriptive statistics such as frequency, percentages, and chi-square test were employed to analyze the surveyed data.

Result: The result suggested 51 (78.43\%) carcass of bird species comprising 11 families. Out of the 125 installed operational turbines, about 35 species of birds were found in 11 families; 27 unidentified molted carcasses of species of birds were significantly impacted with Adama I and II wind farms. In addition, 11 unidentified species of bat were observed as collision victims.

Conclusion: Wind farm establishment and expansion in areas with concentrations of the sensitive species had been avoided. To focus on conservation efforts, we illustrate how knowledge of the structural and environmental factors that influence bird and bat collision can be used to record fatalities in the broader landscape. In order to minimize the mortality rate of birds and bats from collision, a comprehensive environmental impact assessment should be undertaken as precautionary measures.
\end{abstract}

Keywords: Collision impact, Diurnal, Habitat alienation, Migratory, Nocturnal, Species sensitive to wind turbines

\section{Introduction}

Wind energy is one of the most efficient solutions to reduce emissions in the power sector. Globally, wind power is one of the least greenhouse gas intensive energy sources available (Steffen et al. 2004; Katzner et al. 2016). Wind energy was first introduced to a wide range of public with the Kyoto protocol ratified in 2002 (Springer 2002).

Wind power represents one of the most climate-, health-, and environmentally friendly choices of all energy

\footnotetext{
* Correspondence: weldeatesfahunegny@gmail.com

${ }^{1}$ Mekelle Biodiversity Center, Animals Biodiversity Case Team, Ethiopian Biodiversity Institute, Mekelle, Ethiopia

Full list of author information is available at the end of the article
}

production (Jeremy et al. 2014; Gibson et al. 2017; Baidya Roy, 2011). However, wind farms can have negative impacts upon biodiversity especially bird and bat species of great conservation concern (Schuster et al. 2015; De Vos et al. 2014) including direct collision mortality (Rosen, 2003; Getachew 2016; Frick et al. 2017), indirect mortality (Arnett et al. 2007; Strickland et al. 2011), displacement from feeding or nesting area road disturbance (Getachew \& Ayalew, 2016), barrier effects to movement, and habitat degradation or loss (Drewitt \& Langston 2006; Wulff et al. 2016). Collision with anthropogenic factors such as aircraft, communication towers, and wind farms are a great conservation concern for birds and bats (Kunz et al. 2007; Zimmerling et al. 2013; Erickson et al. 2014 \& McClurea
Springer Open

(c) The Author(s). 2020 Open Access This article is licensed under a Creative Commons Attribution 4.0 International License, which permits use, sharing, adaptation, distribution and reproduction in any medium or format, as long as you give appropriate credit to the original author(s) and the source, provide a link to the Creative Commons licence, and indicate if changes were made. The images or other third party material in this article are included in the article's Creative Commons licence, unless indicated otherwise in a credit line to the material. If material is not included in the article's Creative Commons licence and your intended use is not permitted by statutory regulation or exceeds the permitted use, you will need to obtain permission directly from the copyright holder. To view a copy of this licence, visit http://creativecommons.org/licenses/by/4.0/. 
et al. 2018; Korner-Nievergelt et al. 2013). Current studies advocate that wind turbines are the world's new apex predators, wiping out buzzards, hawks, and other carnivorous birds at the top of the food chain (Thaker et al. 2018; McClurea et al. 2018).

Ethiopia has one of the amplest wind resources in Eastern Africa, with velocities ranging from 7 to $9 \mathrm{~m} / \mathrm{s}$ with total exploitable reserves of $10 \mathrm{GW}$ wind energy and 45 GW hydro (Chen 2016). Only less than 1\% of Ethiopia's wind resources and about $5 \%$ of Ethiopia's hydro resources have developed thus far. As of 2014, wind power contributed just $8 \%$, while hydropower accounted for $88 \%$ of Ethiopia's total installed electricity capacity (Chen 2016). Ethiopia commenced to installed wind energy generation capacity in Adama and Ashegoda wind farms, yet there are scant data on the processes that determine collision risk to bird and bat population. The extant 926 bird species of Ethiopia are taxonomically grouped into 27 orders and 155 families, with 24 endemic species and two endemic genera (Hailemariam et al. 2013; Weldemariam et al. 2016; Tesfu et al. 2018). Two hundred fourteen Palearctic migrants have been recorded from Ethiopia, and a large number of these have breeding populations in the country. Of the 665 residents, 30 have migratory forms breeding in the Palearctic region, 37 have non-migratory Palearctic forms, and 69 are mainly African (south of Sahara Desert) or tropical species, which also occur in the Palearctic region (Shimelis \& Afework 2008). There are 199 Palearctic winter visitors, including 21 passage migrants (Kalkidan \& Afework 2011). Seventy-two species of diurnal raptors occur in Ethiopia, 68 of which have believed to migrate at least in part of their ranges. There is an estimated 1300 species of bat (Millon et al. 2018). They are approximately 1240 bat species, representing $20 \%$ of all classified mammal species. So far, 70 bats and 11 fruit bat species were recorded for Ethiopia, 5 of them endemic (African Chiroptera Report 2014). To date, no assessments of bird and bat fatalities have reported at Adama wind farm. The effects of wind energy development on subtler aspects of bird and bat response such as physiological changes that lead to mistrust and stress reactions are unknown. Wind energy industry is found in its infancy, and consequently, there has been little research into the impact to birds and bats. In recent time, Ethiopia commenced to install wind energy generation capacity in Adama I and II wind farm; less than $1 \%$ of Ethiopia's wind resources have developed. However, new projects are underway in order to increase the part of renewable energy production in Ethiopia/East Africa; thus, assessment of wind turbine impact on wildlife is urgently needed. Wind farms require considerable amounts of land, and they can pose a risk to birds and bats' life.

\section{Material and methods Study area}

Adama wind park is located in the strip of land stretching northeast to southwest. Operating wind power project Adama I and II turbines is a site located in Oromia Region $95 \mathrm{~km}$ southeast of Addis Ababa, 3 and $7 \mathrm{~km}$ from Nazareth in the middle of Ethiopia, at elevations of 1741 2173 m (Fig. 1). The central geographical position of the wind project is $39^{\circ} 12^{\prime} 10^{\prime \prime} \mathrm{E}, 8^{\circ} 34^{\prime} 18^{\prime \prime} \mathrm{N}$. Adama I wind power project has an installation capacity of 51 MW (34 turbines with 1.5 MW each). However, it currently comprises 32 turbines operational while 2 turbines are non-operational with generator at ground level. Phase II $153 \mathrm{MW}$ (102 turbines with $1.5 \mathrm{MW}$ each) comprises 93 turbines operational, while 9 turbines are non-operational with gird box at the top of turbine nacelle (Fig. 1). From the study site of Adama I and II, there are about 34 and 102 total turbines of which 32 and 93 found operational while 2 and 9 turbines are non-operational.

It has situated at $8^{\circ} 33^{\prime} \mathrm{N} 39^{\circ} 16^{\prime} \mathrm{E} / 8.55^{\circ} \mathrm{N} 39.27^{\circ} \mathrm{E}$ at an elevation of $1712 \mathrm{~m}$ on the base of Great Rift Valley. Currently, the wind farm will have a potential capacity of $51 \mathrm{MW}$ with a total of 34 wind turbines. The turbines have adjusted parallel on two rows with distance ranging from 200 to $400 \mathrm{~m}$ apart from each other depending on their geographical positions. The selections of the sites to be sampled were done through a process of stratification and randomization. Land use in the area of each Adama wind facility primarily is with agricultural domination, consisting of field crop farms.

\begin{tabular}{|c|c|c|c|c|}
\hline $\begin{array}{l}\text { Wind } \\
\text { farm }\end{array}$ & $\begin{array}{l}\text { No. of } \\
\text { turbines }\end{array}$ & $\begin{array}{l}\text { Operating/non- } \\
\text { operating turbines }\end{array}$ & $\begin{array}{l}\text { Power } \\
\text { output }\end{array}$ & $\begin{array}{l}\text { Generator/ } \\
\text { girds }\end{array}$ \\
\hline $\begin{array}{l}\text { Adama } \\
\text { I }\end{array}$ & 34 & $32 / 2$ & 51 & $\begin{array}{l}\text { With } \\
\text { generator }\end{array}$ \\
\hline $\begin{array}{l}\text { Adama } \\
\|\end{array}$ & 102 & $93 / 9$ & 102 & $\begin{array}{l}\text { With gird } \\
\text { box }\end{array}$ \\
\hline
\end{tabular}

\section{Methods}

A line transects and standardized visual search methods were used to record the fatalities of bird and bat species composition on operational wind farms of Adama I and II. Following similar approach, we also investigated carcasses of bird and bat species beneath the reference turbines. About $30 \%$ of the wind farm turbines should be sampled. The operational wind farms encompassed the 125 wind turbines, while the other non-operational wind farm 11 (reference) served as control with similar topography and land use in Adama I and II wind farms. 


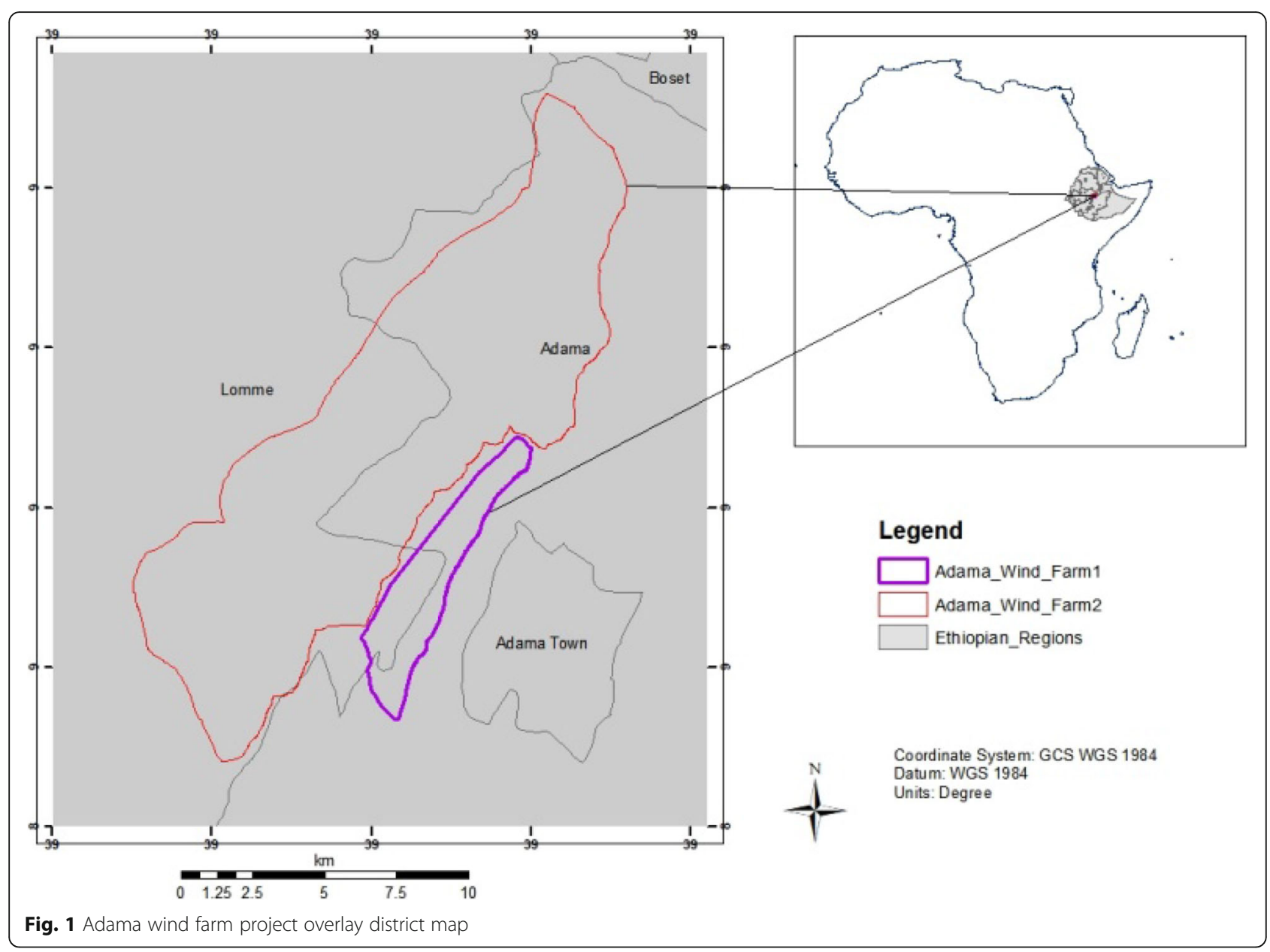

Fatality estimates are commonly undergone based upon a fatality search by human surveyors (Arnett 2006; Smallwood, 2007; Paula et al. 2011). Search width should be equal to the maximum rotor tip height, e.g., for a 120 $\mathrm{m}$ turbine with rotor tip height, the spread of searched area, as a rectangle, square, or circle, should be $60 \mathrm{~m}$ in either direction form the turbine base. This may have to be altered in order to ensure that the searched area encompasses approximately $80 \%$ of the carcasses. Carcass searches have often been used to quantify the impact of existing wind turbines on birds and bats.

The basic procedure involves establishing survey stations randomly throughout the various wind turbines. Semi-structured questionnaires were also administered to 50 wind farm officials and farmers found around Adama wind farm. We used a search protocol very similar to that used by other authors (Morrison \& Sinclair 1998; De Lucas et al. 2004). Thus, we checked $70 \mathrm{~m}$ around all the wind turbines on foot, and when a carcass is found, species name, age, injuries, condition of plumage, date and time of find, distance and orientation to the closest wind turbine, and estimated time of death were recorded.

\section{Statistical analysis}

A non-parametric (Chi-square) test and descriptive statistics using SAS 9.0 software (SAS 2002) were applied to analyze the survey data.

\section{Results}

During the study period in August 2018 and March 2019, more than 51 bird and 9 bat species mortality monitoring surveys have been recorded from Adama I and II wind farms that always combined with daily visits. Four fresh carcasses of birds and five bats were observed near the fully operational turbines. A total of $132 \mathrm{~h}$ was devoted to this task. In the study period, we recorded 1012

Table 1 Respondent reflection on the impact of birds and bats in and around the wind farm

\begin{tabular}{llll}
\hline Birds and bats collided & & \\
\hline & & Frequency & Percent \\
\hline Valid & Local resident of birds and bats & 14 & 28.0 \\
& Migratory birds and bats & 4 & 8.0 \\
& Both & 32 & 64.0 \\
& Total & 50 & 100.0 \\
\hline
\end{tabular}


observations and 1460 (64) individuals in the proximity of the Adama wind farm (Tables 1 and 2). The most abundant birds were passerines, and about eight out of every 10 observations and individuals sighted were species in this group, whereas the remaining $20 \%$ were evenly distributed between raptors and non-passerines. Nine carcasses (five bat and four bird species) were unidentified to the species level since they scavenged highly. Most bat fatalities were recorded in late summer and early autumn. Bird fatalities were more common than bat fatalities (with 88 and $22 \%$, respectively).

\section{Socio-economic aspects of the respondents}

A total of 50 respondents participated in this study, of whom $39(78 \%)$ of them were males and the remaining $11(22 \%)$ were females from Adama wind farms I and II near the kebeles $(d f=1, p<0.0001)$. They were grouped into five age groups, i.e., < 20 years 15 (30\%), 20-29 years 7 (14\%), 30-39 years 22 (44\%), 40-49 years 5 (15\%), 50-59 years 1 (2\%) $(d f=4, p<0.0001)$. According to the respondents' response, what is harmful to bird and bat lives in and near Adam wind farm were the collision with the rotating turbine blades of wind farm $(29(58 \%))$, habitat loss $(13(26 \%))$, agricultural expansion (5 (10\%)), and population expansion (3 (6\%)) $(d f=3, p<0.0001)$. According to the local community response, age of birds are susceptible to wind farm, i.e., 75 young, 18 adults, and 3 old small-sized.

Thirty nine (78\%) community give positive response as birds and bats die due to the rotating turbine blades of wind farm collision, while $11(22 \%)$ did not agree $(d f=$ $1, p<0.1)$. The local community observation part of the wind turbine collides with birds and bats. The status of bird and bat collision in the past 5 years were ranked by the local community as increasing $(3(6 \%))$, the same (16 $(32 \%))$, and the majority do not know the tendency (31 $(62 \%))$. The local birds $(14(28 \%))$, migratory birds (4 $(8 \%))$, and both of them (32 (64\%)) were collided with the wind turbine (Table 1). Birds and bats were collided with the turbine towers at early morning (17 (34\%)), midday (15 (30\%)), early afternoon (13 (26\%)), and all time $(5(10 \%))$, while with respect to seasons, i.e., at summer $(8(16 \%))$, at winter $(27(54 \%))$, and at all seasons $(15(30 \%))(p<0.0001)$. The number of birds and bats that die per week due to the rotating turbine blades of the wind turbine were 1-5 birds and bats 46
(92\%), $5-10$ birds and bats 2 (4\%), 10-15 birds and bats $1(2 \%)$, and $>15$ birds and bats $1(2 \%)(p<0.0001)$ (Fig. $3)$. The local community level of the wind turbine varies with the rotating turbine blades $(3(6 \%))$, turbine nacelle (2\%), hub height $(11(22 \%))$, and tower $(35(70 \%))$. This study has quoted low collision mortality rates per turbine, but in many cases these are based only on found corpses beneath the turbines, leading to underrecording of the actual number of collisions due to scavenger removal. A number of features of wind farms may contribute to their impacts on bird and bat populations.

The effect on migratory birds and bats was also positioned: $30(60 \%)$ agreed there is a negative effect on them, while $4(8 \%)$ did not agree, and $16(32 \%)$ did not know the effect on the migratory of bird and bat. About $6(12 \%)$ of the local community believe that the wind turbine attracts bird and bat, and 26 (52\%) did not agree that bird and bat were attracted by the wind turbines. The feeling of the local community around the wind farm were as follows: 42 were interested, 2 were not interested, and 6 were without any impression. Regarding the status of bird and bat death by wind turbines in the last 5 years, there are about $3(6 \%)$ increasing, $16(32 \%)$ the same, and $31(62 \%)$ unknown $(d f=2, p<0.0001)$. Wind turbine areas are within landscape features that are frequently used by birds and bats such as valleys or steep slopes. Obviously, wind energy is not free of problems, although these are small when compared with those associated to other sources of energy. Wind turbines can negatively affect the birds and bats that develop in their surroundings.

According to the local community thinking, the collision of bird and bat species in Adam wind farm had been frequently observed in both the resident and migratory species (64\%) (Table 1).

The main factors that affect the diversity of bird and bat species in and around Adama wind farm were direct impact from wind farm collision (19 (43.25\%)), settlement expansion $(2(4.5 \%))$, and habitat loss and agricultural intensification (5 (11.4\%)) (Table 2). The adverse biodiversity-related impacts of wind power facilities mainly involve birds, bats, and natural habitats. Bird species groups of special concern are birds of prey such as raptors, migratory birds, and grassland birds with aerial flight display.

Table 2 Factors that affect birds and bats in and around the wind farm

\begin{tabular}{lllll}
\hline No. & Factors & Mean & Standard deviation (SD) & Frequency (\%) \\
\hline 1 & Direct impacts from wind farm collision & 0.076 & 0.501 & $19(43.25 \%)$ \\
2 & Habitat loss & 0.164 & 1.089 & $5(11.4 \%)$ \\
3 & Agricultural expansion & 0.164 & 1.089 & $5(11.4 \%)$ \\
4 & Settlement expansion & 0.164 & 1.089 & $2(4.5 \%)$ \\
\hline
\end{tabular}


According to the researchers' team field observation, wind farm officials, and local respondents' idea, wind farm collision mortality, habitat loss, agricultural expansion, and population expansion to both bird and bat species were the major impact factors (Fig. 2a). Nine families carcasses were observed: Accipitridea and Columbidea consisted the highest with 8\%; Falconidea, Corvidea, and Bucorvidea with 2\%; and Ciconidea, Pandionidae, Aedeidea, and Bucerotidae with 1\% (Fig. 2b). The wind farm was located with high density, and the collision risk of low reproduction rate of bird of prey and bat species. The bird and bat carcasses were observed beneath the wind turbines. The land cleared to set up the turbines also affects the homegarden birds and bats.

Sample surveys were conducted in both seasons in wind farm cropland, shrub, and pasture. Birds of prey fall victim to collisions with wind turbines relatively more often than other bird species. Some species of raptors are among the most frequently reported collision victims. There is a need to understand the underlying reasons for this phenomenon on birds of prey and wind farms. This indicated that the role of top-down control is high in the agricultural lands since more mammals are found in the area. There is a positive correlation between bird and bat activity and fatality rates at Adama wind turbines. The highest numbers of bird fatalities were found at wind turbines near habitats that are attractive to birds with migration routes and near dumping sites. Clearly, a risk of collision with rotors exists only when birds and bats are in flight with the rotorswept area which may affected by turbulence caused by the rotors. The flight behavior including the height at which different birds fly vary considerably between species. The majority of the bat carcasses were found from June to September, with greater abundance in July and August.
Due to differences in topography and vegetation, as well as in flocking and migratory behavior, the applicability of bird and bat mortality at Adama wind farms varies. The wind farm was built in a mountainous area, i.e., agricultural lands with high population of nocturnally migrating birds, bats, and diurnally flocking raptors. Some studies demonstrate that bird and bat species fatalities occur primarily on nights with low wind speed and typically increase immediately before and after the passage of storm fronts. Generally, wind farms established in sensitive areas such as bottlenecks are high-risk areas for collisions between migrants and wind turbine blades under certain conditions. In addition, the solid waste disposal facilities found near the Adama wind farm attracted for birds to collide.

\section{Discussion}

Wind turbines are the world's new apex predators that roar out eagles, hawks, and other carnivorous birds at the top of the food chain (Thaker et al. 2018). They are disrupting links of feeding/roosting/nesting areas. They also affect bats because their roosting places, feeding areas, and migrating routes coincide with the most suitable placements for wind turbines. Adama wind farm places near agricultural lands, rivers, top of distinct hills and mountains areas. The wind turbines are attractive to both birds and bats, but the source of attraction remains speculative. The moving rotor blades most commonly kill birds and bats. Therefore, the longer the blades are, the more birds and bats they can kill as the area cover bigger (Erickson et al. 2014). Another cause of death is internal hemorrhaging caused by the pressure drop behind the rotor blades (Arnett \& Baerwald 2013; Arnett 2012; European Commission 2011). Not only do wind farms affect the mortality of bird and bats, but the

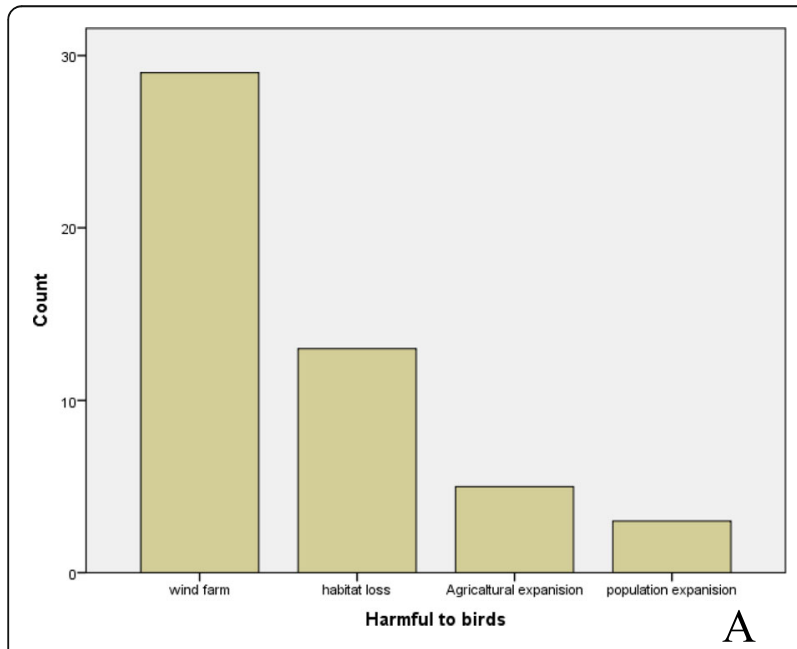

\section{9 carcass}

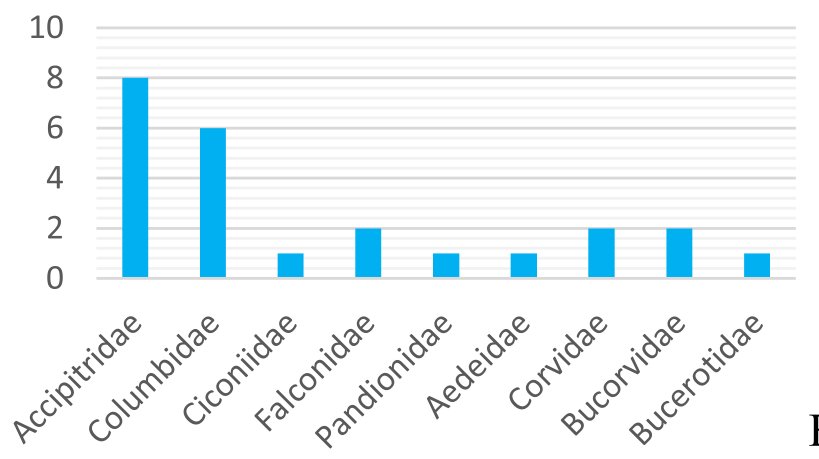

Fig. 2 Seasons that bird and bat species collide at wind farm 
construction of the wind farms leads to a loss of their habitat as trees are cut down to clear the land.

Bats and soaring birds have naturally low reproductive rates and low natural mortality, so scaled upwind power in sensitive sites could threaten some species (De Lucas et al. 2012). Besides, to collision mortality, the presence/ noise of turbines may also prevent birds and bats from using the area for feeding, breeding, and nesting close to wind turbines (Arnett et al. 2011). There is some clue that wind turbines may be obstacles to bird and bat movements. Instead of flying between the wind turbines, birds and bats may fly nearby the group. Whether this is a problem will depend on the size of the wind farm, spacing of turbines, the extent of displacement of flying birds and bats, and their ability to compensate for increased energy expenses (National Research Council 2007; McClurea et al. 2018). The cumulative effects of large wind farm installations may be considerable if bird and bat movements are consequently displaced. Today, bird displacement from offshore and onshore projects is well documented in only a few studies and for a few species (Steffen et al. 2004; Roscioni et al. 2013; Erickson et al. 2014). This may lead to the interference of ecological links between feeding, breeding, and roosting areas.

For birds, it is important to understand flight corridors and establish spatial buffers away from these areas, or provide corridors between the clusters of turbines aligned with main flight trajectories for species to fly through (Drewitt \& Langston 2006). For bats, they also move along linear structures such as rivers and river valleys (Furmankiewicz \& Kucharska 2009) as well as forest edges and hedges (Kelm et al. 2014).

Collisions at wind turbines do not appear to be chance events. Bird and bat species probably are attracted to turbines either directly, as turbines may resemble roosting sites (Cryan et al. 2014), or indirectly because turbines attract insects on which birds and bats feed (Rydell et al. 2010a, 2010b). More than 71 bird and bat individual species were collision victims due to Adama wind farm in our investigation. Literatures show that terrestrial wind farms have documented highest collision risk of Accipitriformes/Accipitridae (raptors and birds of prey) (Thaxter et al. 2017). Similarly, our study showed that Accipitriformes had the highest rates of collision. Among other orders/family, Piciformes-Picidae (woodpeckers), FalconiformesAccipitriformes Accipitres-Accipitridae (hawks, buzzards, and eagles), Columbiformes-Columbidae (pigeons, doves), Ciconiiformes-Ciconiidae (storks), FalconiformesFalconidae (falcons, caracaras) Accipitriformes-Pandionidae (osprey), Pelecaniformes-Aedeidae (bitterns, herons, and egrets), Passeriformes-Corvidae (crows), BucerotiformesBucorvidae (Abyssinian hornbill), Bucerotiformes-
Bucerotidae (hornbill), Pelecaniformes-Ardeidae (little egret), and Molossidae-Chiroptera (free-tailed bat) were also vulnerable, but many of water birds were not investigated.

Although there was less variation in predicted mortality of bird and bat species, some were associated with relatively high rates of collision. Diurnal raptors are relatively frequent fatalities particularly in Adama II where these species are more common since there were a dumping site near the turbines. Turbines that use lattice support towers offer more perching sites for raptors, encouraging higher raptor occupancy in the immediate vicinity of the rotor swept area (Johnson et al. 2016) than large, modern turbines on tubular support towers. Weather patterns may influence bat fatalities in wind farms. The estimated total number of bird and bat fatalities at wind energy facilities is likely several orders of magnitude lower than other leading anthropogenic sources of birds and bats mortality (Powlesland, 2009; Thaker et al., 2018). The relationship between bird and bat behavior and collision risk, especially near the rotor swept area, is complex to understand. Certain species that forage for prey in close proximity to turbines (specifically raptors and birds of prey) appear to have higher fatality rates, while other species that actively fly around wind turbines (pigeons, doves, and crows) appear to avoid collisions with turbines (Johnson et al. 2016). Higher prey density (e.g., small mammals) has presumed to be a principal factor responsible for high raptor use and collision rates at Adama I and II wind farms. The bird and bat collision risk has developed to predict future fatalities based on the primary survey. Globally, hundreds of millions of birds die each year (Fig. 3) in collisions with manmade structures, including glass windows and buildings, communication towers, and wind turbines (Vié et al. 2009; Turner et al. 2007).

Light is also a pollutant that causes direct mortality to birds and bats by confusing their nocturnal navigation mechanisms and drawing to collide with man-made structures such as communication towers, buildings, and wind farms (Turner et al. 2007; Steffen et al. 2004). The continued loss of critical breeding and migratory stopover habitat to human development poses a devastating threat to wild bird populations (Bird Life International 2004). The construction site pictured has been totally wiped clean of the mature secondary forest that once existed here. Without suitable breeding habitat, birds cannot maintain their populations. Without key migratory stopovers, birds cannot even reach their breeding grounds. As human populations increase, this problem will likely worsen (Turner et al. 2007). Collision fatalities at wind energy facilities are considered by many to be one of the greatest threats to bat populations in developed countries (Barclay et al. 2007; Colby et al., 2009). 

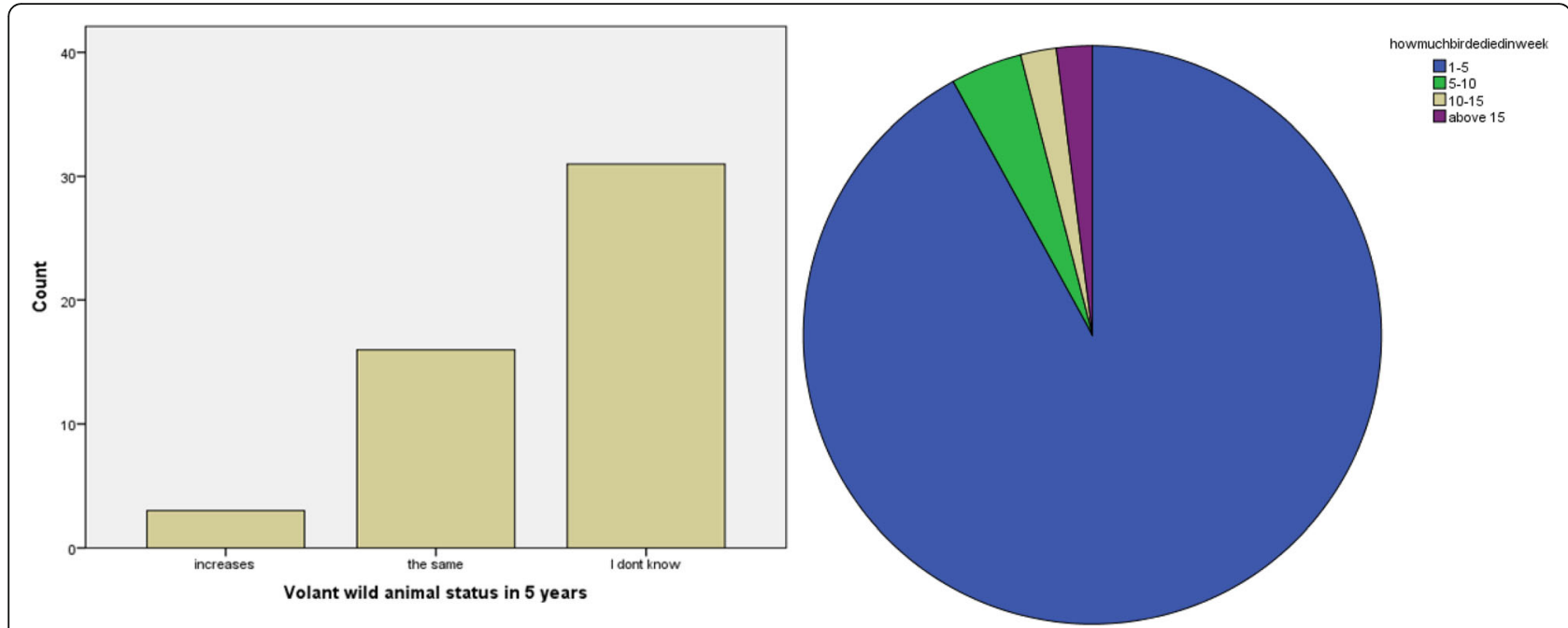

Fig. 3 Farmers' response in the case of how much birds die in a week due to wind farm collision

Bat mortality at wind turbine generators is of greater magnitude than avian mortality (Kunz et al. 2007; Arnett et al. 2007). Mitigation of bird and bat direct impacts have been limited due to limited knowledge of how and why they are being killed by wind turbine generators (Thaker et al., 2018). For this reason, intensive studies of bird and bat species migration patterns and behaviors at wind energy developments have initiated. Our specific objectives were to focus on how wind energy developments influence birds and bats. The discovery of numerous birds and bats in Adama shows that the development of wind energy facilities may have a significant adverse impact on bird and bat population. Consequently, appropriate consideration to birds and bats should be implemented in the planning and operation of wind turbines to develop ecologically sustainable wind energy facilities.

Bird and bats appear to actively seek out turbines and investigate turbine towers, nacelles, and rotors, thus exposing them to high collision risk. Bird and bat species may also use the wind turbines as intermediate resting and mating roost sites (Arnett et al. 2007). A fundamental gap in our current knowledge preconstruction assessment of risk is that no linkages exist between preconstruction assessments and postconstruction of the wind farm fatalities for bird and bat species.

\section{Conclusion}

In addition to wind farms, there are numerous other anthropogenic causes of faunal mortality of which the great majority are unquantified. Modern wind farms near areas that are attractants for birds and bats may be particularly dangerous. The greatest hazard to the ecosystem of Adama wind farm comes from their impact on birds and bats that can be injured by flying into turbine blades. Although it is important to note that this is at a rate far less than other sources of injury, bird and bat species are likely to benefit overall from reduced climate change. Nocturnal birds and bats may also arise from physical exhaustion associated with light-induced disorientations. Impact minimization methods that assumed to make turbine blades more visible to birds and bats should be proposed to reduce collisions with wind turbines. Researchers need to explore ways to convey conservation principles in a manner that draws people together with win-win-win rather than fostering an attitude of confrontation. By engaging in dialogues with local policy-makers, ornithologist can help to make birdand bat-friendly technology; such opportunities are more widely available in the places where they live and work. In conclusion, the development of wind power poses a threat to birds and bats, and several species of which are at risk. For operational wind turbines, mitigation measures such as raising the cut-in speed and shutdown during critical periods make it possible to significantly reduce bird and bat mortality. The cumulative impacts for birds and bats clearly are acceptable. As a result, authors conclude that population effects are unlikely; provided wind farm establishments in areas with concentrations of the sensitive species are avoided. Minimize, to the extent practicable, the area disturbed by pre-construction site monitoring and testing activities and installations. Avoid locating wind energy facilities in areas identified as having a demonstrated and unmitigatable high risk to birds and bats. The main management implication should correctly know about the population data of both birds and bats with the cumulative effect of wind turbines. Spatial zoning and site policy criteria, used effectively, can mediate between biodiversity and 
wind energy interests and ensure that targets are met in both spheres. Sensitive mapping is a powerful tool to inform locational decisions for wind energy development and should be used by regulators and industry in transparent decision-making.

\section{Recommendation}

Conducting extensive post-construction fatality searches for a full season of bird and bat movement and activity for smart wind energy development. Wind farm development projects must endeavor to avoid impacts on wildlife. Wind farm should be far away from linking habitats that are significant for bird and bat conservation concern. Wind farms are not developed where there is a demonstrable risk to bird and bat habitat. Impact assessments need to consider the full set of potential impacts at site, landscape, and population levels, and to account fully for diurnal, seasonal, and annual variation in bird and bat distributions and numbers.

\section{Acknowledgments}

The Ethiopian Biodiversity Institute sponsors this study. The authors want to acknowledge all the local people for actively participating in the study and the EECO wind farm project officials for their permission of the field survey practices. Authors also sincerely thank all who have been involved in the process of producing this paper.

\section{Authors' contributions}

All authors conducted the fieldwork, designed, read, and approved the final research paper.

\section{Funding}

The Ethiopian Biodiversity Institute financially supported this research work.

\section{Availability of data and materials}

It is possible to request authors for the data used and analyzed during the current study.

\section{Ethics approval and consent to participate}

The authors have the government's permission to collect data from the wind farm.

\section{Consent for publication \\ Not applicable.}

\section{Competing interests}

All authors have no competing interests.

\section{Author details}

${ }^{1}$ Mekelle Biodiversity Center, Animals Biodiversity Case Team, Ethiopian Biodiversity Institute, Mekelle, Ethiopia. ${ }^{2}$ Animal Biodiversity Directorate, Ethiopian Biodiversity Institute, Addis Ababa, Ethiopia.

Received: 11 October 2019 Accepted: 2 June 2020

Published online: 29 June 2020

\section{References}

African Chiroptera Report. (2014). African Bats, Pretoria.

Arnett, E. B. (2006). A preliminary analysis on the use of dogs to recover bat fatalities at wind energy facilities. Wildlife Society Bulletin, 34, 14401445.

Arnett, E. B. (2012). Impacts of wind energy development on wildlife: challenges and opportunities for integrating science, management. In J. P. Sands, D. M.
SJ, L. A. Brennan, \& M. J. Schnupp (Eds.), Wildlife science: with management, (pp. 213-237). New York: Taylor and Francis.

Arnett, E. B., \& Baerwald, E. F. (2013). Impacts of wind energy development on bats: implications for conservation. In R. A. Adams, \& S. C. Peterson (Eds.), Bat evolution, ecology, and conservation, (pp. 435-456). New York: Springer.

Arnett, E. B., Huso, M. M. P., Schirmacher, M. R., \& Hayes, J. P. (2011). Altering turbine speed reduces bat mortality at wind-energy facilities. Frontiers in Ecology and the Environment, 9(4), 209-214.

Arnett, E. B., Inkley, D. B., Johnson, D. H., Larkin, R. P., Manes, S., Manville, A. M., .. Thresher, R. (2007). Impacts of wind energy facilities on wildlife and wildlife habitat. Wildlife Society Technical Review 07-2. Bethesda, Maryland, USA: The Wildife Society.

Baidya Roy, S. (2011). Simulating impacts of wind farms on local hydrometeorology. Aerodyn. Journal of Wind Engineering \& Industrial Aerodynamics, 99(14), 491-498.

Barclay, R. M. R., Baerwald, E. F., \& Gruver, J. C. (2007). Variation in bird and bat fatalities at wind energy facilities: assessing the effects of rotor size and tower height. Canadian Journal of Zoology, 85, 381-387.

Bird Life International (2004). State of the world's birds: indicators for our changing world, (pp. 1-76). Cambridge, UK: BirdLife International.

Chen, Y. (2016). A comparative analysis: the sustainable development impact of two wind farms in Ethiopia. In China-Africa Research Initiative, School of Advanced International Studies. Washington, DC: Johns Hopkins University Retrieved from http://www.sais-cari.org/publications.

Colby W David, Robert D, Geoff L, David ML, Robert JM, Michael TS, \& Bo Søndergaard. (2009). Wind turbine sound and health effects: an expert panel review, Canadian Wind Energy Association.

Cryan, P. M., Gorresen, P. M., Hein, C. D., Schirmacher, M. R., Diehl, R. H., Huso, M. M., ... Dalton, D. C. (2014). Behavior of bats at wind turbine. Proceedings of the National Academy of Sciences Oct, 111(42), 15126-15131.

De Lucas, M., Ferrer, M., Bechard, M. J., \& Munoz, A. R. (2012). Griffon vulture mortality at wind farms in southern Spain: distribution of fatality and active mitigation measures. Biological Conservation, 147, 184-189.

De Lucas, M., Janss, G. F. E., \& Ferrer, M. (2004). The effects of a wind farm on birds in a migration point: the Strait of Gibraltar. Biodiversity and Conservation, 13, 395-407.

De Vos, J. M., Joppa, L. N., Gittleman, J. L., Stephens, P. R., \& Pimm, S. L. (2014). Estimating the normal background rate of species extinction. Conservation Biology, 29(2), 452-462.

Drewitt, A., \& Langston, R. H. W. (2006). Assessing the impacts of wind farms on birds. Ibis, 148, 29-42

Erickson, W. P., Wolfe, M. M., Bay, K. J., Johnson, D. H., \& Gehring, J. L. (2014). A comprehensive analysis of small-passerine fatalities from collision with turbines at wind energy facilities. PLOS ONE, 9(9), e107491.

European Commission. (2011). Guidance document: wind energy developments and natural 2000. EU Guidance on wind energy development in accordance with the EU nature legislation.

Frick, W. F., Baerwald, E. F., Pollock, J. F., Barclay, R. M. R., Szymanski, J. A., Weller, T. J., ... McGuire, L. P. (2017). Fatalities at wind turbines may threaten population viability of a migratory bat. Biological Conservation, 209, 172-177.

Furmankiewicz, J., \& Kucharska, M. (2009). Migration of bats along a large river valley in southwestern Poland. Journal of Mammology, 90(6), 1310-1317.

Getachew, M. (2016). Green dilemma of wind farm on Avifauna: future ecological considerations of wind energy expansion in Ethiopia. The Journal of Zoology Studies, 3(3), 46-57.

Getachew, M., \& Ayalew, S. (2016). Green dilemma of wind farm on Avifauna: future ecological considerations of wind energy expansion in Ethiopia. The Journal of Zoology Studies, 3(3), 46-57.

Gibson, L., Wilman, E. N., \& Laurance, W. F. (2017). How green is 'green' energy? Trends Ecological Evolution, 32, 922-935.

Hailemariam, A., Meheretu, Y., \& Tsegazeabe, H. H. (2013). Community composition and abundance of residential birds in selected church forests, Tigray Region, Northern Ethiopia. Scientific Research and Essays, 8(22), 1038-1047.

Jeremy, M., Alicia, C., \& Grant, B. (2014). Wind energy, climate and health: evidence for the impacts of wind generated energy in Australia.

Johnson, D. H., Loss, S. R., Smallwood, K. S., \& Erickson, W. P. (2016). Avian fatalities at wind energy facilities in North America: a comparison of recent approaches. Human-Wildlife Interactions, 10(1), 7-18.

Kalkidan, E., \& Afework, B. (2011). Species composition, relative abundance and distribution of the avian fauna of Entoto Natural Park and escarpment, Addis Ababa. SINET: Ethiopian Journal of Science, 34(2), 113-122. 
Katzner, T., Bennett, V., Miller, T., Duerr, A., Braham, M., \& Hale, A. (2016). Wind energy development: methods for assessing risks to birds and bats preconstruction. Human-Wildlife Interactions, 10(1), 42-52.

Kelm, D. H., Lenski, J., Kelm, V., Toelch, U., \& Dziock, F. (2014). Seasonal bat activity in relation to distance to hedgerows in an agricultural landscape in central Europe and implications for wind energy development. Acta Chiropterologica, 16(1), 65-73

Korner-Nievergelt, F., Brinkmann, R., Niermann, I., \& Behr, O. (2013). Estimating bat and bird mortality occurring at wind energy turbines from covariates and carcass searches using mixture models. PLOS ONE, 8(7), e67997.

Kunz, T. H., Arnett, E. B., Erickson, W. P., Hoar, A. R., Johnson, G. D., Larkin, R. P., \& Tuttle, M. D. (2007). Ecological impacts of wind energy development on bats: questions, research needs, and hypotheses. Frontiers in Ecology and the Environment, 5(6), 315-324.

McClurea, C. J. W., Martinsonb, L., \& Allisonc, T. D. (2018). Automated monitoring for birds in flight: proof of concept with eagles at a wind power facility. Biological Conservation, 224, 26-33.

Millon, L., Colin, C., Brescia, F., \& Kerbiriou, C. (2018). Wind turbines impact bat activity, leading to high losses of habitat use in a biodiversity hotspot. Ecological Eng, 112, 51-54.

Morrison, M. L., \& Sinclair, K. (1998). Avian Risk and Fatality Protocol. Colorado: National Renewable Energy Laboratory (NREL), Golden.

National Research Council (2007). Environmental impacts of wind-energy projects. Washington, D.C: The National Academies Press.

Paula, J., Costa, M. L., Silva, M. J., Mascarenhas, R., Costa, H., \& Mascarenhas, M. (2011). Dogs as a tool to improve bird-strike mortality estimates at wind farms. Journal for Nature Conservation, 19, 202-208.

Powlesland, R. G. (2009). Impacts of wind farms on birds: a review. Science for conservation., 289, 33-45.

Roscioni F, Russo D, Di Febbraro M, Frate L, Carranza ML, \& Loy A. (2013). Regional-scale modelling of the cumulative impact of wind farms on bats. Biodiversity and Conservation, 22(8), 1821-1835.

Rosen, Z. M. (2003). Win-win ecology: how Earth's species can survive in the midst of human enterprise. Oxford: Oxford University Press.

Rydell, J., Bach, L., Dubourg-Savage, M. J., Green, M., Rodrigues, L., \& Hedenström, A. (2010a). Bat mortality at wind turbines in northwest Europe. Acta Chiropterologica, 12, 261-274.

Rydell J, Bach L, Doubourg-Savage M, Green M, Rodrigues L, \& Hedenström A. (2010b). Mortality of bats atwind turbines links to nocturnal insect migration? Eur J Wildl Res 56:823-827.

SAS (2002). Statistical Analysis System. Cary, NC, USA: Institute Inc.

Schuster, E., Bulling, L., \& Köppel, J. (2015). Consolidatihe state of knowledge: a synoptical review of wind energy' wildlife effects. Environmental Management, 56, 300-331.

Shimelis, A., \& Afework, B. (2008). Species composition, relative abundance and distribution of bird fauna of riverine and wetland habitats of Infranz and Yiganda at southern tip of Lake Tana, Ethiopia. Tropical Ecology, 49(2), 199-209.

Smallwood, K. S. (2007). Estimating wind turbine-cause bird mortality. Journal of Wildlife Management, 71, 2781-2791.

Springer, U. (2002). The market for tradeable GHG permits under the Kyoto Protocol: a survey of model studies. Energy Economics, 25(5), 527-551.

Steffen, W., Sanderson, A., Tyson, P. D., Jäger, J., Matson, P. A., Moore, B., .. Wasson, R. J. (2004). Global change and the Earth system: a planet under pressure. Heidelberg: Springer.

Strickland, M. D., Arnett, E. B., Erickson, W. P., Johnson, D. H., Morrison, M. L., Shaffer, J. A., \& WarrenHicks, W. (2011). Comprehensive guide to studying wind energy/wildlife interactions. Washington, DC: Prepared for the National Wind Coordinating Collaborative.

Tesfu, F., Weldemariam, T., \& Asersie, M. (2018). Impact of human activities on biosphere reserve: a case study from Yayu biosphere reserve, Southwest Ethiopia. International Journal of Biodiversity and Conservation, 10(7), 319-326.

Thaker, M., Zambre, A., \& Bhosale, H. (2018). Wind farms have cascading impacts on ecosystems across trophic levels. Nature Ecology and Evolution Vol., 2, 1854-1858

Thaxter, C. B., Buchanan, G. M., CarrJ, B. S. H. M., Newbold, T., Green, R. E., Tobias, J. A., ... Pearce-Higgins, J. W. (2017). Bird and bat species' global vulnerability to collision mortality at wind farms revealed through a trait-based assessment. Proceedings of the Royal Society Biological Sciences, 284, 20170829.

Turner, W. R., Brandon, K., Brooks, T. M., Costanza, R., Da Fonseca, B. G. A., \& Portela, R. (2007). Global conservation of biodiversity and ecosystem services. Bioscience, 57(10), 868-873.
Vié, J. C., Hilton-Taylor, C., \& Stuart, S. N. (2009). Wildlife in a changing world. An analysis of the 2008 IUCN Red List of Threatened Species, (p. 180). Gland, Switzerland: IUCN

Weldemariam, T., Tesfu, F., \& Getachew, M. (2016). Avifauna diversity in Kafa biosphere reserve: knowledge and perception of villagers in Southwest Ethiopia. Ecology and Evolutionary Biology., 1(2), 7-13.

Wulff, S. J., Butler, M. J., \& Ballard, W. B. (2016). Assessment of diurnal wind turbine collision risk for grassland birds on the Southern Great Plains. Journal of Fish and Wildlife Management, 7(1), 129-140.

Zimmerling, J. R., Pomeroy, A. C., Entremont, M. V.'., \& Francis, C. M. (2013). Canadian estimate of bird mortality due to collisions and direct habitat loss associated with wind turbine developments. Avian Conservation and Ecology, $8(2), 10$.

\section{Publisher's Note}

Springer Nature remains neutral with regard to jurisdictional claims in published maps and institutional affiliations.

\section{Submit your manuscript to a SpringerOpen ${ }^{\circ}$ journal and benefit from:}

- Convenient online submission

- Rigorous peer review

- Open access: articles freely available online

- High visibility within the field

- Retaining the copyright to your article

Submit your next manuscript at $\boldsymbol{\nabla}$ springeropen.com 